\title{
EXPERIMENTAL INVESTIGATION ON SURFACE ROUGHNESS IN ELECTRICAL DISCHARGE TURNING OF Ti-6Al-4V ALLOY
}

\begin{abstract}
Summary
This study presents a novel EDM turning process specially designed and developed to generate precise cylindrical forms on hard and difficult-to-machine materials. For this purpose, a specially designed turning spindle is used. The spindle was mounted on a conventional die-sinking EDM machine to rotate the workpiece. Axially symmetric parts can be manufactured by feeding the shaped tool into the rotating workpiece. In this way an axisymmetric workpiece can be made with small tools at both macro and micro levels. Effects of machining parameters, such as the current, pulse-on time, rotational speed, flushing pressure, and duty factor, on the surface roughness of Ti-6Al-4V alloy in electrical discharge turning were investigated. Taguchi's design of experiment technique was used. Analysis of variance and regression analysis were performed on experimental data. The signal-to-noise ratio analysis was employed to find the optimal condition.
\end{abstract}

Key words: $\quad$ Electrical discharge machining, Electrical discharge turning, Surface roughness, Axisymmetric workpieces

\section{Introduction}

Electrical discharge machining (EDM) is an electro-thermal process where material removal is achieved by electrical discharges occurring between the tool and the workpiece [1]. Among various EDM processes, the die-sinking EDM is used extensively to machine complex cavities in full hardened and stabilized die steels, to avoid the problem of dimensional variability [2]. Small cylindrical parts made of advanced conductive materials, which are difficult to machine by a conventional cutting methods such as milling and turning, can be produced by an electrical discharge machine. The EDM process can be improved by setting up an external rotary axis on a conventional electrical discharge machine and by feeding the tool electrode against the rotating workpiece in order to produce axisymmetric geometries. This improved process named electrical discharge turning (EDT) can be utilized for producing cylindrical forms and helical profiles on high-strength, temperature resistant (HSTR) alloys widely used in the aeronautical and automotive industries. The concept of EDM turning is illustrated in Fig.1. 


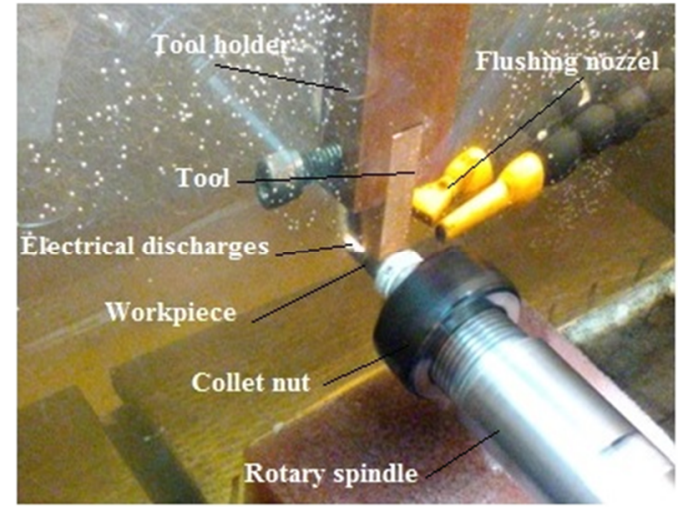

Fig. 1 Concept of EDT process

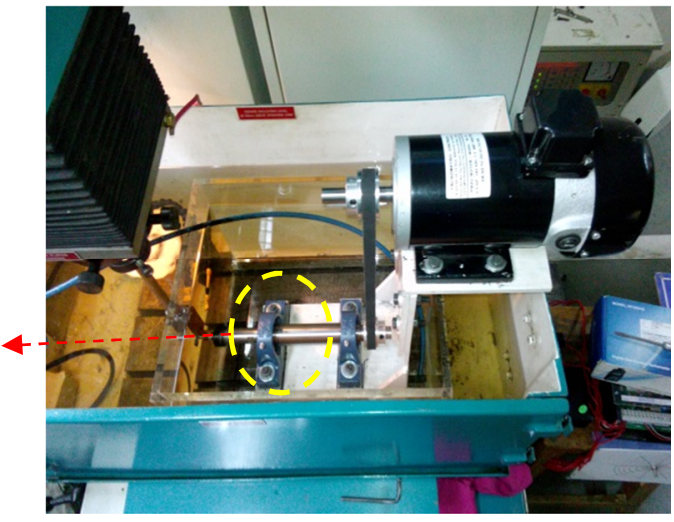

Fig. 2 Experimental set up of the EDT process

The EDT process has been developed from wire electrical discharge turning (WEDT) in order to achieve a high degree of accuracy, surface finish, and cylindricity in the straight turning and in the form turning of a hard-to-machine material with high slenderness ratio. Fig. 2 shows a precise rotary spindle setup which was added to the conventional EDM machine to give rotary motion to the workpiece. A die-sinking EDM machine is widely used for turning aerospace honey-comb seals where internal and external seals are machined to a burr-free finish with internal or external diameters from 300mm-1400mm [3-6]. An example of a machined part produced by the EDT method is shown in Fig. 3. The surface produced by EDM is matte finish and complicated. The surface integrity explains the mechanical, metallurgical, chemical, and topological conditions of the surface region, which in turn depends on the machining parameters such as the applied current, voltage, and pulse duration.

As surface roughness ( $\mathrm{Ra})$ is one of the most important parameters in manufacturing, various investigations have been carried out considering various input parameters in order to improve the surface roughness of the part. Soni and Chakraverti [7] performed an experimental study on the drilling operation performed on a rotary EDM. Titanium and copper-tungsten were chosen as the workpiece and the tool material, respectively. The authors found that rotation of the tool electrode improves the material removal rate. However, this results in high surface roughness. The idea of employing EDM to machine cylindrical parts for manufacturing small diameter pins was put forward by doctor Masuzawa at the University of Tokyo [8]. Small pins can be utilized as the tool in the micro EDM application [9]. Guu et al. [10] study the influence of workpiece rotation during electrical discharge machining of the AISI D2 tool steel using a copper electrode. Experimental findings indicate that surface finish improves with an increase in the workpiece rotational speed. Rohney et al. [11] presented the application of cylindrical wire electrical discharge turning (CWEDT) for the profile turning of metal bond diamond wheels. Using a mathematical model, Jun et al. [12] investigated the surface integrity of a wire EDM turned part. Using statistical analysis, Mohammadi et al. [13] investigated the effect of machining parameters on the surface finish and roundness of cemented steel in wire electrical discharge turning. Investigation results demonstrate that voltage, power, time-off, and spindle speed have the strongest effect on the surface roundness $\mathrm{Ra}$. As the values of power and voltage increase and those of spindle speed and time-off decrease, Ra increases. Haddad et al. [14] used the response surface methodology approach to investigate experimentally the surface roughness of the AISI D3 tool steel in the CWEDT process. Janardhan et al. [15] used the pulse train data analysis to study the effect of process parameters on the material removal, surface roughness, and roundness. Weingartner et al. [16] investigated the WEDM process on high speed rotating workpieces and found that the volume of the eroded craters increases with an increase in the relative speed. 
Although extensive research has been done on the electrical discharge machining of various materials and on optimizing EDM parameters, no research, to the best of our knowledge, has been reported on electrical discharge machining of titanium in the context of turning. In view of that fact, the surface roughness of a part turned by means of the conventional EDM process is investigated in this study and possible ways of adjusting the process parameters to achieve better surface finish are explored using statistical methods. Five machining parameters were considered to study the effect of the EDM process on surface roughness. In the present research, Taguchi's design of experiment technique was employed to perform more accurate and less costly experiments. Three different analyses were performed on the data obtained from the experiments. This was done by characterizing significant factors by means of the analysis of variance (ANOVA) technique. Then, regression analysis was conducted to establish the relationship between the factors and the response. Subsequently, signal-to-noise $(\mathrm{S} / \mathrm{N})$ ratio analysis was conducted to find the optimal settings and factor levels. Finally, optimal process parameters were verified by three experiments.

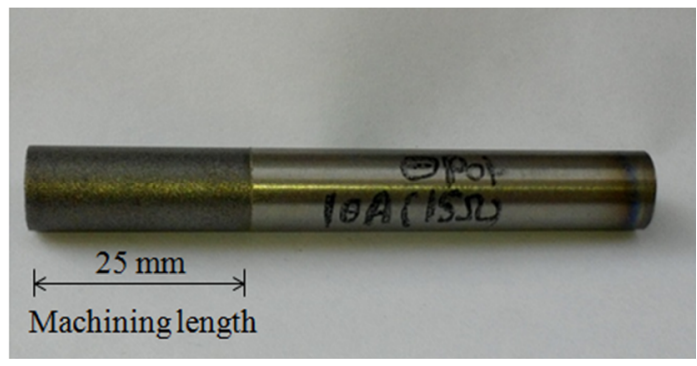

Fig. 3 A cylindrical EDT part

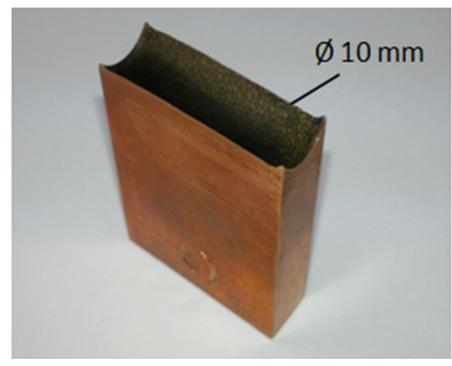

Fig. 4 Tool electrode after machining

\section{Experimental setup and equipment}

The material selected for testing was titanium alloy because this material is difficult to machine. It is extensively used in aerospace, automobile, chemical, and biomedical applications due to its excellent physical, metallurgical, and mechanical properties such as high strength-to-weight ratio, high temperature stability, and good corrosion resistance. A cylindrical bar (10 $\mathrm{mm}$ in diameter) made of titanium alloy was tested. The machining time for each experiment was fixed to 30 minutes. During that time, workpieces were machined from $10 \mathrm{~mm}$ to $7.96 \mathrm{~mm}$. The tool electrode made of electrolytic copper with dimensions of 40 $\mathrm{mm} \times 25 \mathrm{~mm} \times 8 \mathrm{~mm}$ was manufactured on a CNC vertical machining centre (Agni BMV45TC 24, BFW make). A photo of the tool electrode after machining is shown in Fig. 4. Industrial grade EDM oil was used as a dielectric fluid for side flushing. All the experiments were performed on an Electronica $500 \times 300$ ZNC EDM machine at reverse polarity. Surface roughness was measured using a surface roughness tester (SV 514, Mitutoyo make) with 0.8 mm cut-off length (according to DIN EN ISO 3274:1998). The surface roughness was measured at three different sections and the average of three values was considered. The recast layer was revealed by a standard metallurgical procedure using cutting, grinding, and polishing. Cylindrical workpieces were sliced in radial direction. The surface of sliced cross sections were polished and etched to observe the sub-surface damage. Kroll's reagent (1-3 ml $\mathrm{HF}, 2-6 \mathrm{ml} \mathrm{HNO}_{3}$ and $100 \mathrm{ml}$ pure water) was used to etch the polished surface of titanium workpieces.

\subsection{Design of experiments}

The accuracy and effectiveness of an experimental program depends on careful planning and execution of the experimental procedure. In order to achieve the aforesaid objective, the Taguchi orthogonal array $(\mathrm{OA}) \mathrm{L}_{18}\left(2^{1} \times 3^{7}\right)$ was adopted for the design of experiments. Thus, 18 experiments were conducted at parameter levels shown in Table 1. 
Each run is replicated three times so that the total number of runs is 54 . Note that the experiments were run in random order. Current, pulse on-time, spindle rotational speed, flushing pressure, and duty factor, each at three levels, are adopted as factors (variable parameters) which vary during the experiments according to the design of experiment. The results of the surface roughness values measured in each experimental run are presented in Table 1. In this research, only the main effects of factors are of interest and their interactions are excluded from the data analysis. Therefore, the degree of freedom (DOF) for this study is calculated as in Equation 1 [19].

$$
\begin{aligned}
\text { DOF } & =\text { number of factors } \times \text { number of factor level }-1 \\
& =5 \times 3-1=10
\end{aligned}
$$

Table 1 Experimental layout of an $\mathrm{L}_{18}$ orthogonal array

\begin{tabular}{|c|l|l|l|l|l|l|c|c|c|}
\hline Run & C & Ton & RPM & FP & DF & \multicolumn{3}{|c|}{ Surface roughness Ra $(\mu \mathrm{m})$} \\
\hline \multicolumn{9}{|l|}{} & \multicolumn{2}{l|}{ Replicate 1 } & Replicate 2 & Replicate 3 \\
\hline 1 & 5 & 5 & 50 & 0 & 1 & 2.40 & 2.15 & 2.42 \\
\hline 2 & 5 & 10 & 100 & 0.25 & 5 & 2.40 & 2.57 & 2.28 \\
\hline 3 & 5 & 15 & 150 & 0.50 & 9 & 2.80 & 3.54 & 3.20 \\
\hline 4 & 20 & 5 & 50 & 0.25 & 5 & 3.17 & 2.42 & 2.86 \\
\hline 5 & 20 & 10 & 100 & 0.50 & 9 & 3.58 & 3.76 & 3.37 \\
\hline 6 & 20 & 15 & 150 & 0 & 1 & 4.18 & 4.19 & 4.61 \\
\hline 7 & 35 & 5 & 100 & 0 & 9 & 3.17 & 3.25 & 3.55 \\
\hline 8 & 35 & 10 & 150 & 0.25 & 1 & 4.93 & 4.40 & 4.67 \\
\hline 9 & 35 & 15 & 50 & 0.50 & 5 & 5.16 & 5.28 & 5.43 \\
\hline 10 & 5 & 5 & 150 & 0.50 & 5 & 2.00 & 2.12 & 2.20 \\
\hline 11 & 5 & 10 & 50 & 0 & 9 & 2.40 & 3.60 & 3.42 \\
\hline 12 & 5 & 15 & 100 & 0.25 & 1 & 4.30 & 3.27 & 3.98 \\
\hline 13 & 20 & 5 & 100 & 0.50 & 1 & 3.00 & 3.35 & 3.16 \\
\hline 14 & 20 & 10 & 150 & 0 & 5 & 3.38 & 3.52 & 3.29 \\
\hline 15 & 20 & 15 & 50 & 0.25 & 9 & 4.20 & 4.41 & 4.26 \\
\hline 16 & 35 & 5 & 150 & 0.25 & 9 & 3.26 & 3.50 & 3.15 \\
\hline 17 & 35 & 10 & 50 & 0.50 & 1 & 4.30 & 3.95 & 4.44 \\
\hline 18 & 35 & 15 & 100 & 0 & 5 & 4.55 & 5.10 & 5.14 \\
\hline
\end{tabular}

C- Current, Ton- pulse-on time, RPM- spindle rotational speed, FP- flushing pressure, DF- duty factor

\section{DATA ANALYSIS}

Fig. 5 shows five plots of the main effects of five different input parameters on the surface roughness of the workpiece machined surface. Note that the data mean is used to determine the effect of each factor. Fig. 5 shows that the applied current and pulse-on time have the most significant effects on the surface roughness. Both parameters and the surface roughness are directly proportional, i.e. if the values of the current and pulse-on time increase, the surface roughness increases significantly. This happens because when the value of current increases, more violent electrical discharges strike the workpiece surface and produce deeper craters. As a result, the surface processed by EDM is deteriorated. Similarly, when the value of pulse-on time is increased, more heat energy is transferred to the workpiece surface and more material is melted. The effects of spindle rotational speed, flushing pressure, and duty factor on surface roughness are also presented in Fig. 5. As indicated, none of the parameters 
have a significant effect on surface roughness except the duty factor which has the opposite effect on it; the value of surface roughness decreases as that of the duty factor increases. Fig. 6 shows the plot of main effects of five selected parameters on the $\mathrm{S} / \mathrm{N}$ ratio for surface roughness. As it is clearly seen, by increasing the values of current and pulse-on time, the sensitivity of the system to the noise factors increases for the surface roughness, whereas by increasing the values of spindle rotational speed and duty factor, the sensitivity of the system to the noise factors decreases for this response. The system is less sensitive to the noise factors at the mean level of duty factor, and flushing pressure has a negligible effect on the sensitivity of the system. ANOVA has often been employed by researchers since it overcomes the shortcomings of graphical assessment. ANOVA is used here for discussing and interpreting data. Before any inference can be made based on the ANOVA table data, the assumptions based on the ANOVA process have to be checked and verified as follows.

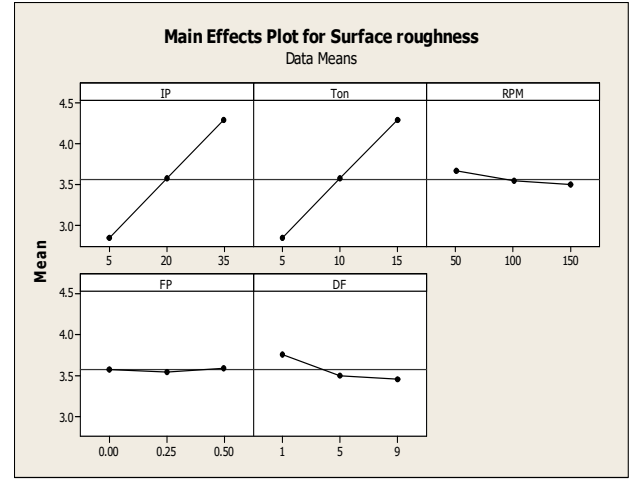

Fig. 5 Effects of five factors on surface roughness

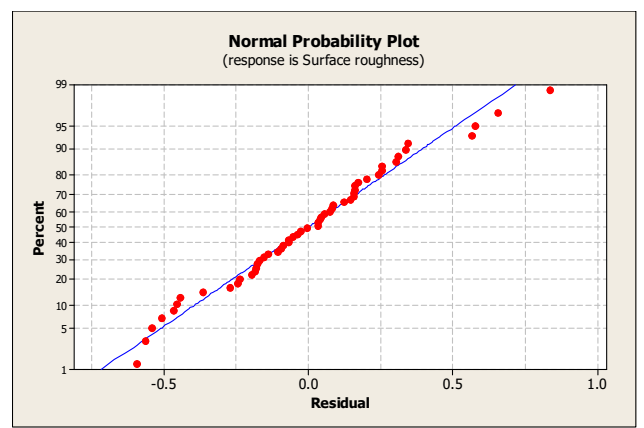

Fig. 7 Normal probability plot of residuals

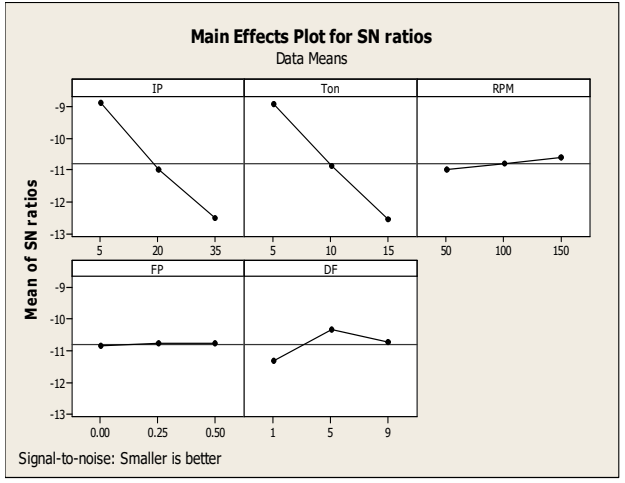

Fig. 6 Plot of the main effects on the $\mathrm{S} / \mathrm{N}$ ratio for $\mathrm{Ra}$

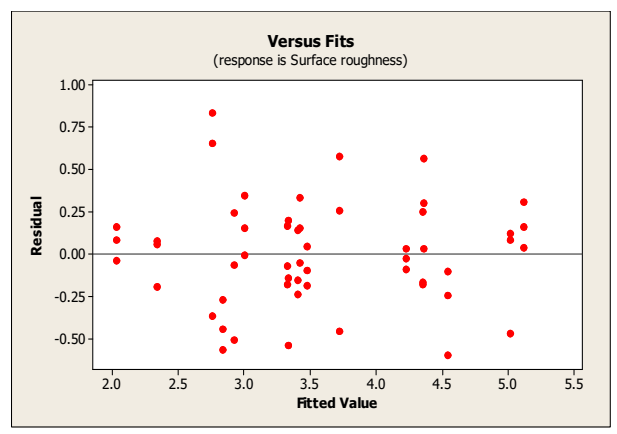

Fig. 8 Plot of residuals versus fitted values

Fig. 7 shows the normal plot of residuals. This plot is used to test the normal distribution of errors. If the underlying error distribution is normal, this plot will resemble a straight line. The distribution of points in Fig. 7 shows that the error normality assumption is valid [17]. The other two assumptions are shown valid by means of the plot of residuals versus fitted values. Fig. 8 shows the plot of residuals versus fitted values for surface roughness. The structureless distribution of data points above and below the abscissa (fitted values) shows that the errors are independently distributed and the variance is constant [18]. In the above discussion, ANOVA assumptions (error normality, error independency, and variance constancy) are proved not to be violated through this experimentation, so ANOVA can be performed and the inference made on the basis of its table will be valid. Table 2 presents the ANOVA table for surface roughness. It can be seen from the table that the current, pulse-on time, and duty factor have the most significant impacts on surface roughness at a confidence level of $95 \%$. Therefore, the P-values which are less than 0.05 indicate that the null hypothesis should be rejected and thus the effect of the respective parameter is significant. 
Table 2 ANOVA table for surface roughness using the adjusted SS for tests

\begin{tabular}{|l|l|l|l|l|l|l|}
\hline Source & DF & Seq. SS & Adj. SS & Adj. MS & F & P \\
\hline IP & 2 & 19.0420 & 19.0420 & 9.5210 & 84.67 & 0.000 \\
\hline Ton & 2 & 19.0678 & 19.0678 & 9.5339 & 84.78 & 0.000 \\
\hline RPM & 2 & 0.2777 & 0.2777 & 0.1389 & 1.23 & 0.301 \\
\hline FP & 2 & 0.0220 & 0.0220 & 0.0110 & 0.10 & 0.907 \\
\hline DF & 2 & 1.0120 & 1.0120 & 0.5060 & 4.50 & 0.017 \\
\hline Error & 43 & 4.8355 & 4.8355 & 0.1125 & & \\
\hline Total & 53 & 44.2571 & & & & \\
\hline
\end{tabular}

\subsection{Regression analysis}

The relationship between machining parameters and surface roughness was characterized by a mathematical model called regression equation. Since it is assumed that the machining parameters and surface roughness are linearly related to each other, the derived regression equation is as follows:

$\mathrm{Ra}=1.4975+0.0484 \mathrm{IP}+0.1455 \mathrm{~T}$ on $-0.0017 \mathrm{RPM}+0.0356 \mathrm{FP}-0.0385 \mathrm{DF}$

Table 3 indicates that the above mentioned regression model is the best one of the models that can be used with these parameters and parameter levels by $\mathrm{R}^{2}{ }_{\text {(adj.) }}$ test. The $\mathrm{R}^{2}$ value indicates that the predictors explain $88.6 \%$ of the variance in surface roughness. $\mathrm{R}^{2}{ }_{\text {(adj.) }}$ is $87.4 \%$, which accounts for the number of predictors in the model. Both values show that the data are fitted well. Table 4 is the ANOVA table for regression analysis which shows that the model estimated by regression procedure is significant at an $\alpha$-level of 0.05 .

Table 3 Table of coefficients for regression analysis

\begin{tabular}{|l|c|c|c|c|}
\hline Predictor & Coefficient & SE coefficient & $\mathrm{T}$ & $\mathrm{P}$ \\
\hline Constant & 1.4975 & 0.1946 & 7.69 & 0.000 \\
\hline Current & 0.048481 & 0.003598 & 13.48 & 0.000 \\
\hline Pulse-on-time & 0.14556 & 0.01079 & 13.49 & 0.000 \\
\hline Spindle speed & -0.001700 & 0.001079 & -1.58 & 0.122 \\
\hline Flushing pressure & 0.0356 & 0.2159 & 0.16 & 0.870 \\
\hline Duty factor & -0.03854 & 0.01349 & -2.86 & 0.006 \\
\hline $\mathrm{S}=0.323783$ & R-Sq. $=88.6 \%$ & R-Sq. (adj.) $=87.4 \%$ & \\
\hline
\end{tabular}

Table 4 ANOVA table for regression analysis

\begin{tabular}{|l|l|l|l|l|l|}
\hline Source & DF & SS & MS & F & P \\
\hline Regression & 5 & 39.2250 & 7.8450 & 74.83 & 0.000 \\
\hline Residual error & 48 & 5.0321 & 0.1048 & & \\
\hline Total & 53 & 44.2571 & & & \\
\hline
\end{tabular}

\section{$3.2 \mathrm{~S} / \mathrm{N}$ ratio analysis}

To find the optimum parameter levels, the signal-to-noise $(\mathrm{S} / \mathrm{N})$ ratios were calculated from the observed values. The type of problem which is dealt with here is "the-lower-thebetter" (LB) [17]. For such type of problems, the $\mathrm{S} / \mathrm{N}$ ratio is expressed as in Equation 2:

$$
\eta=-10 \log \left[\frac{1}{n} \sum_{i=1}^{n} y_{i}^{2}\right]
$$


where, $\eta$ denotes the $S / N$ ratio calculated from the observed values (units: $d B$ ), $y_{i}$ represents the response value of the $i^{\text {th }}$ experiment and $n$ is the number of replications of each experiment. The logic behind the $\mathrm{S} / \mathrm{N}$ ratio analysis is to find a setting of parameters in which signals are predominant. This rationale eventually leads to a situation in which the system is least sensitive to noises [16]. Table 5 shows the mean $\mathrm{S} / \mathrm{N}$ ratios obtained for each parameter level. ANOVA is performed to find the important parameters which affect the sensitivity of the process (Table 6). The table shows that the current and pulse-on time are the most dominant parameters with a zero $\mathrm{p}$-value, which changes the $\mathrm{S} / \mathrm{N}$ ratio. Based on this strategy, combinations of optimal parameters for 3 levels are shown in Table 5.

Table $5 \mathrm{~S} / \mathrm{N}$ values $(\mathrm{dB})$ for surface roughness

\begin{tabular}{|l|l|l|l|l|l|}
\hline Level & C & Ton & RPM & FP & DF \\
\hline 1 & $\mathbf{- 8 . 9 0 0}$ & $\mathbf{- 8 . 9 5 3}$ & -10.986 & -10.844 & -11.298 \\
\hline 2 & -10.993 & -10.891 & -10.807 & -10.788 & $\mathbf{- 1 0 . 3 6 1}$ \\
\hline 3 & -12.516 & -12.565 & $\mathbf{- 1 0 . 6 1 7}$ & $\mathbf{- 1 0 . 7 7 8}$ & -10.751 \\
\hline Rank & 1 & 2 & 4 & 5 & 3 \\
\hline
\end{tabular}

Table 6 ANOVA table of $\mathrm{S} / \mathrm{N}$ ratios for surface roughness

\begin{tabular}{|l|l|l|l|l|l|l|}
\hline Source & DF & Seq. SS & Adj. SS & Adj. MS & F & P \\
\hline C & 2 & 39.5617 & 39.5617 & 19.7808 & 36.60 & 0.000 \\
\hline Ton & 2 & 39.2059 & 39.2059 & 19.6030 & 36.27 & 0.000 \\
\hline RPM & 2 & 0.4087 & 0.4087 & 0.2043 & 0.38 & 0.698 \\
\hline FP & 2 & 0.0152 & 0.0152 & 0.0076 & 0.01 & 0.968 \\
\hline DF & 2 & 2.6582 & 2.6582 & 1.3291 & 2.46 & 0.155 \\
\hline Residual error & 7 & 3.7833 & 3.7833 & 0.5405 & & \\
\hline Total & 17 & 85.6330 & & & & \\
\hline
\end{tabular}

\subsection{SEM results}

The machined surface in EDM can be described by the surface characteristics such as surface roughness, surface cracks, recast layer, micro structural changes, and other elements. SEM micrographs of the EDT surfaces are taken in order to examine the surface integrity and the sub surface of electrical discharge turned part made of Ti-6Al-4V alloy. It should be noted that these SEM images are related to the central area of the machined surface. Fig. 9 (a) and (b) shows the surface for the minimum and maximum Ra values respectively. The machined workpiece which had a minimum Ra value of $2.20 \mu \mathrm{m}$ (experiment number 10, Table 1) was machined at $5 \mathrm{~A}$ current and $5 \mu$ s pulse-on time and the machined workpiece which had a maximum Ra value of $5.43 \mu \mathrm{m}$ (experiment number 9, Table 1) was machined at $35 \mathrm{~A}$ current and $15 \mu \mathrm{s}$ pulse-on time. At lower current density, less damage is done to the workpiece surface. The craters formed on the surface are shallow and therefore low $\mathrm{Ra}$ values are obtained, as shown in Fig. 9 a. As the value of current increased, the density of discharge energy also increased and hence larger and deeper craters were formed. The result was increased surface roughness and the occurrence of cracks as shown in Fig. 9 b. 

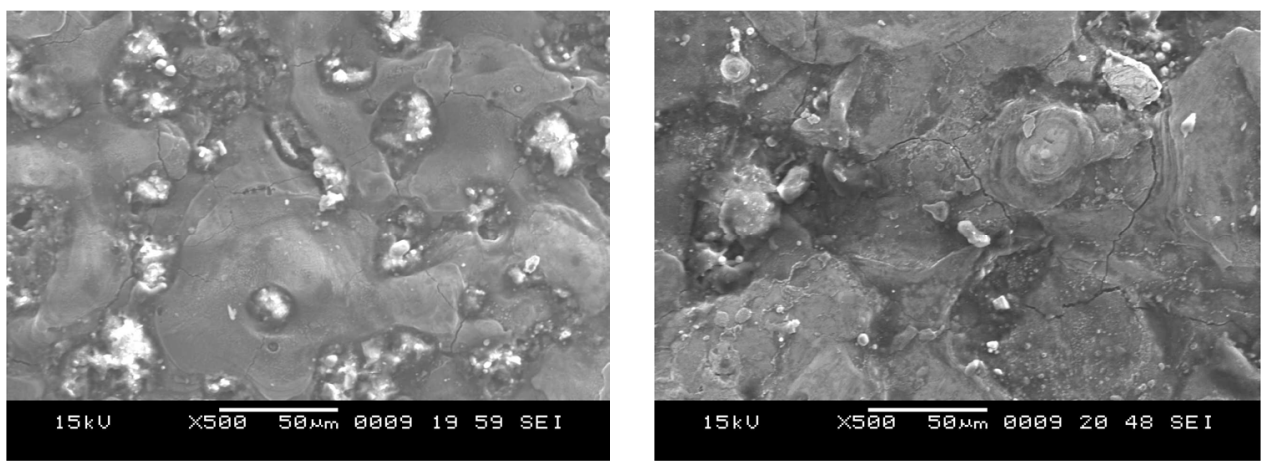

Fig. 9 SEM micrographs of the surface with minimum Ra (a) and that with maximum $\mathrm{Ra}$ (b)
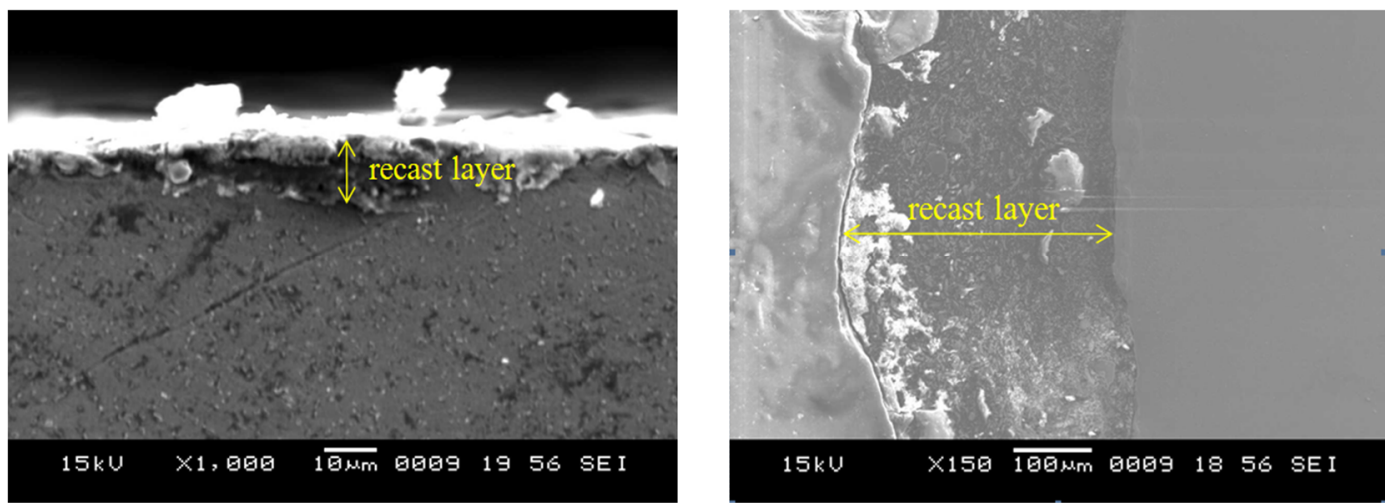

Fig. 10 SEM micrographs of the surface cross section at low $\mathrm{Ra}$ (a) (Current $=5$, Ton $=5, \mathrm{RPM}=150, \mathrm{Fp}=0.5, \mathrm{DF}=5)$, at high $\mathrm{Ra}(\mathrm{b})(\mathrm{Current}=35, \mathrm{Ton}=15, \mathrm{RPM}=50, \mathrm{Fp}=0.5, \mathrm{DF}=5)$

SEM micrographs of the cross section of the titanium alloy under the low and the high surface roughness are shown in Fig. 10 (a) (b) respectively. The existence of recast layer or white layer on the top surface of machined workpiece is due to the solidification of the molten material which is not flushed away by dielectric fluid. Below the recast layer is a heataffected zone (HAZ). Finally, below the recast layer and the HAZ, bulk material of the machined workpiece can be noted. As shown in Fig. 10 (b), the thickness of the recast layer under the higher surface roughness is increased proportionally to the increase in the current. The heat-affected zone may exist but it cannot be identified in Fig. 10 (a) and (b).

\subsection{Confirmation runs}

The purpose of the confirmation run is to validate the conclusions drawn during the analysis phase. Optimum levels of the machining parameters were used for the prediction and confirmation of the improvement in output characteristics. In this study, a new experiment was designed with a combination of parameters along with their levels A1 B1 C3 D3 E2 to obtain surface roughness. The final step is to predict and verify the improvement in the output characteristics. The estimated $\mathrm{S} / \mathrm{N}$ ratio $(\eta)$ using the optimal level of the parameters can be calculated as:

$$
\eta_{\text {opt }}=\eta_{m}+\sum_{j=1}^{k}\left(\eta_{j}-\eta_{m}\right)
$$

Where,

$\eta_{m}=$ total mean of $\mathrm{S} / \mathrm{N}$ ratio.

$\eta_{j}=$ means of $\mathrm{S} / \mathrm{N}$ ratio at optimum level.

$\mathrm{k}=$ number of main design parameter. 
The results of confirmation run are presented in Table 7. The improvement in signal-tonoise ratio from the initial machining setting to the predicted machining setting is $3.44 \mathrm{~dB}$. Thus, surface roughness is decreased by 1.48 times, which means that, the surface roughness is greatly improved by introducing the Taguchi technique for optimization.

Table 7 Results of confirmation runs for surface roughness

\begin{tabular}{|l|c|c|c|}
\hline \multirow{2}{*}{ Initial machining parameter } & \multicolumn{2}{c|}{ Optimal machining parameter } \\
\cline { 3 - 4 } & A2B2C2D2E2 & Prediction & Experiment \\
\hline Levels & 3.598 & 2.242 & A1B1C3D3E2 \\
\hline Surface roughness & -11.11 & -7.01 & 2.419 \\
\hline S/N ratio & & & -7.67 \\
\hline
\end{tabular}

\section{CONCLUSION}

This paper presents a new concept of electrical discharge turning. A prototype system was designed and fabricated to conduct experiments. In this study, the effects on the surface roughness of machining parameters in the EDT process have been investigated experimentally. The investigation was performed on the Ti-6Al-4V alloy because of its wide application in the aerospace and defence industry, fabrication of medical implants, and in the automotive industry. Based on the experimental results, one can draw the following conclusions:

- The most important parameters affecting the surface roughness of a workpiece processed by the EDT process have been identified as the current, pulse-on time, and duty factor.

- An optimum parameter setting for minimum surface roughness has been identified as follows: current at level 1, pulse-on time at level 1, rotational speed at level 3, flushing pressure at level 3, and duty factor at level 2 .

- The identified decrease of 1.17 in surface roughness indicates that it is possible to optimize surface roughness by using the proposed statistical technique.

- Surface cracks, craters, recast layer, and heat-affected zone were noticed on the machined surface. All these effects can be minimized by keeping electrical parameters at lower values.

- These experimental results confirmed the validity of the Taguchi method used for improving the machining performance and optimizing the machining parameters in the EDT operation and for ensuring the success of the experimentation.

\section{REFERENCES}

[1] Gjeldum, N., Veža, I. and Bilic, B.: Prediction of the material removal rates of cylindrical wire electrical discharge turning processes, Transactions of FAMENA, 35, 2011, pp 27-38.

[2] Ferreira, J. C.: A study of die helical thread cavity surface finish made by $\mathrm{Cu}-\mathrm{W}$ electrodes with planetary EDM, The International Journal of Advanced Manufacturing Technology, 34, 2007, pp 1120-1132. DOI:10.1007/s00170-006-0687-z

[3] Daneshmand, S., Neyestanak, A., Monfared, V. (2016). Modelling and investigating the effect of input parameters on surface roughness in electrical discharge machining of CK45. Tehnički vjesnik, 23(3). pp 725-730. DOI:10.17559/TV-20141024224809

[4] Gohil, V., and Puri, Y. M.: Turning by electrical discharge machining: A review, Proceedings of the Institution of Mechanical Engineers, Part B; Journal of Engineering Manufacture, 2015, DOI: $10.1177 / 0954405415590560$ 
[5] Gohil, V., and Puri, Yogesh M.: Statistical analysis of material removal rate and surface roughness in electrical discharge turning of titanium alloy (Ti-6Al-4V), Proceedings of the Institution of Mechanical Engineers, Part B; Journal of Engineering Manufacture, 2016, DOI: 10.1177/0954405416673104.

[6] Gohil, V., and Puri, Y. M.: Experimental investigation of surface roughness in electrical discharge turning process, Proceedings of the 19th International ESAFORM Conference on Material Forming, 1769, No. 1, 2016, pp. 050001-6. AIP Publishing. DOI:10.1063/1.4963429

[7] Soni, J. S., and Chakraverti, G.: Machining characteristics of titanium with rotary electro-discharge machining, Wear, 171, 1994, pp 51-58. DOI:10.1016/0043-1648(94)90347-6

[8] Masuzawa, T., and Tönshoff, H. K.: Three-dimensional micromachining by machine tools, CIRP Annals Manufacturing Technology, 46, 1997, pp 621-628. DOI:10.1016/S0007-8506(07)60882-8

[9] Rajurkar, K. P., and Yu, Z. Y.: 3D micro-EDM using cad/cam, CIRP Annals-Manufacturing Technology, 49, 2000, pp 127-130. DOI:10.1016/S0007-8506(07)62911-4

[10] Guu, Y. H., and Hocheng, H.: Effects of workpiece rotation on machinability during electrical-discharge machining, Materials and Manufacturing Processes, 16, 2001, pp 91-101. DOI:10.1081/AMP-100103699

[11] Rhoney, B. K., Shih, A. J., Scattergood, R.O., Akemon, J. L., Gust, D. J., Grant, M. B.: Wire electrical discharge machining of metal bond diamond wheels for ceramic grinding, International Journal of Machine Tools and Manufacture, 42, 2002, pp 1355-1362. DOI:10.1016/S0890-6955(02)00056-1

[12] Qu, J., Shih, A. J., Scattergood, R. O.: Development of the cylindrical wire electrical discharge machining process, part 2: surface integrity and roundness, Journal of manufacturing science and engineering, 124, 2002, pp 708-714. DOI:10.1115/1.1475989

[13] Mohammadi, A., Tehrani, A. F., Emanian, E., Karimi, D.: A new approach to surface roughness and roundness improvement in wire electrical discharge turning based on statistical analyses, The International Journal of Advanced Manufacturing Technology, 39, 2008, pp 64-73. DOI:10.1007/s00170007-1179-5

[14] Haddad, M. J., Alihoseini, F., Hadi, M., Hadad, M., Tehrani, A. F., Mohammadi, A.: An experimental investigation of cylindrical wire electrical discharge turning process, The International Journal of Advanced Manufacturing Technology, 46, 2010, pp 1119-1132. DOI:10.1007/s00170-009-2171-z

[15] Janardhan, V., Samuel, G. L.: Pulse train data analysis to investigate the effect of machining parameters on the performance of wire electro discharge turning (WEDT) process, International Journal of Machine Tools and Manufacture, 50, 2010, pp 775-788. DOI:10.1016/j.ijmachtools.2010.05.008

[16] Weingärtner, E., Wegener, K., Kuster, F.: Wire electrical discharge machining applied to high-speed rotating workpiece, Journal of Materials Processing Technology, 212, 2012, pp 1298-1304. DOI:10.1016/j.jmatprotec.2012.01.005

[17] Montgomery, D. C.: Design and analysis of experiments, John Wiley and Sons, New Delhi, India 2008.

[18] Montgomery, D. C., and Runger, G. C.: Applied statistics and probability for engineers, John Wiley and Sons, New Delhi, India 2010.

[19] Phadke, M. S.: Quality engineering using robust design, Prentice Hall of India, New Delhi, India 1995.

$\begin{array}{cll}\text { Submitted: } & 03.3 .2016 & \text { Vikas Gohil } \\ & & \text { Y. M. Puri } \\ \text { Accepted: } & 22.7 .2016 & \text { CAD-CAM Centre } \\ & & \text { Department of Mechanical Engineering } \\ & & \text { Visvesvaraya National Institute of } \\ & \text { Technology, Nagpur- 440010 (MS) } \\ & \text { INDIA } \\ & \text { E-mail: 2vikasgohil@gmail.com }\end{array}$

